\title{
STUDY TO ESTABLISH CORRELATION BETWEEN VITAMIN D, PTH AND BMD IN TYPE 2 DIABETIC PATIENTS
}

\author{
Azhar Ali Khan', Virendra Kumar Yadav² \\ 1Associate Professor, Department of Medicine, Baba Raghav Das Medical College, Gorakhpur, Uttar Pradesh. \\ 2Junior Resident, Department of Medicine, Baba Raghav Das Medical College, Gorakhpur, Uttar Pradesh.
}

\begin{abstract}
\section{BACKGROUND}

Type 2 Diabetes Mellitus still remains one of the leading causes of morbidity and mortality. Diabetic patients are prone to osteoporosis. The development of osteoporosis in diabetes is also promoted by the coexistence of chronic microvascular complications of diabetes, which also affect the bone marrow blood vessels. Diabetic osteopathy is a significant comorbidity of diabetes and is characterised by microarchitectural changes that decrease bone quality and reduction of bone strength leading to an increased risk of bone fracture in diabetes. There is high prevalence of vitamin D deficiency and hyperparathyroidism in uncontrolled diabetic patients, which further leads to osteopenia or osteoporosis.

Aims and Objectives- To establish correlation between vitamin D, PTH and BMD with diabetic control and complications of type 2 diabetic patients.
\end{abstract}

\section{MATERIALS AND METHODS}

An observational study was conducted in Medicine Department of Nehru Hospital, BRD Medical College, Gorakhpur. Data entry and analysis was done by IBM SPSS Version 22 using Fisher exact test and Pearson Chi-square test. A total of 100 clinically diagnosed patients of type-2 diabetes mellitus were selected for the study. Duration of study was 1 year (Jan 2017 to Dec 2017). All the patients were subjected to detailed clinical history, examination and relevant investigations like HbA1c, BMD, vitamin D, PTH, urine microscopy, fundus etc. were done in all patients.

\section{RESULTS}

There was high prevalence of abnormal BMD (62\%) in T2DM patients. Most of the patients with osteoporosis (30\%) had uncontrolled T2DM (86.66\%) with low vitamin D (86.66\%) and raised PTH (66.67\%), while in osteopenic (32\%) patients 67.66\% had uncontrolled diabetes, $68.75 \%$ had low vitamin D and $37.50 \%$ had raised PTH (p value $=0.002$ ). In type 2 diabetic patients, vitamin D deficiency was present in $60 \%$ patients and hyperparathyroidism in $34 \%$ patients.

\section{CONCLUSION}

Patients with uncontrolled diabetes had high prevalence of microvascular complications. The microvascular complications cause decreased mineralisation of bone and increased risk of abnormal BMD via various metabolic alterations. In poorly controlled diabetic patients, there is increased prevalence of raised PTH and low vitamin D levels which causes osteoporosis and further worsens blood sugar control. Patients with osteoporosis had poor blood sugar control and more prevalence of microvascular complications, which further leads to osteoporosis via vicious cycle.

\section{KEYWORDS}

T2DM, Microvascular Complications, BMD, PTH and Vitamin D.

HOW TO CITE THIS ARTICLE: Khan AA, Yadav VK. Study to establish correlation between vitamin D, PTH and BMD in type 2 diabetic patients. J. Evolution Med. Dent. Sci. 2018;7(18):2257-2260, DOI: 10.14260/jemds/2018/508

\section{BACKGROUND}

Diabetes mellitus is an endocrine disorder, perhaps as old as the origin of mankind. It still remains one of the leading causes of morbidity and mortality till date. The well-known late complications of diabetes are microvascular diseases including nephropathy, retinopathy, neuropathy and macrovascular diseases such as acute coronary syndrome, peripheral vascular disease and stroke. ${ }^{1}$ The complications of diabetes are related to long-term elevation of blood glucose

'Financial or Other Competing Interest': None.

Submission 21-03-2018, Peer Review 13-04-2018,

Acceptance 20-04-2018, Published 30-04-2018.

Corresponding Author:

Dr. Virendra Kumar Yadav,

Kaliyapur Village, Pipargoan Post,

Aurai District, S. R. N.

Bhadohi-221301,

Uttar Pradesh.

E-mail: virendrakgmc009@gmail.com

DOI: $10.14260 /$ jemds $/ 2018 / 508$ concentration (hyperglycaemia). Hyperglycaemia results in the formation of advanced glycation end products (AGEs) These AGEs acts to prime endothelial cells and monocytes, making them more susceptible to stimuli that induce the cells to produce the inflammatory mediators. Accumulation of AGEs in plasma and tissues of diabetic patients has been linked to diabetic complications. The accumulation of advanced glycation end products (AGEs) in collagen leads to inferior bone quality and strength. Furthermore, glycated collagen inhibits expression in osteoblasts. ${ }^{2}$ Another indirect effect of hyperglycaemia is glycosuria, which causes hypercalciuria leading to decreased levels of calcium in the body and poor bone quality and fastens bone loss. ${ }^{3}$

Osteoporosis is defined as a combination of reduced bone mass and altered bone quality with microarchitectural abnormalities, resulting in decreased bone strength with an increased risk of fractures. ${ }^{4}$ Based on the present definition, both bone density and quality, which encompass the structural and material properties of bone are important factors in the determination of bone strength. Diabetic 
osteopathy is a significant comorbidity of both forms of diabetes and is characterised by microarchitectural changes that decrease bone quality leading to an increased risk of bone fracture in both types of diabetes. ${ }^{5}$ The fracture risk of T1DM increases because of a decrease of BMD. ${ }^{6}$ In patients with T1DM, the impaired bone formation is a result of absolute deficiency of insulin and insulin-like growth factor-1 (IGF-1), which leads to lower values of peak bone mass. In both types of diabetes, bone displays inferior quality and strength.7 Dual energy x-ray absorptiometry (DXA) scan can diagnose osteoporosis in the early stages before broken bones can occur. ${ }^{8}$

Epidemiological studies in Asian-Indian populations indicate that elderly patients with proximal femoral fractures had high prevalence of vitamin D deficiency and these patients had significantly low BMD compared with healthy controls. These osteoporosis fractures tend to occur earlier in Indian population than in their western counterparts and they are more common in women. It is believed that half of all women and one-third of all men will sustain an osteoporotic fracture during their lifetime. Regardless of the source, however, low level of serum vitamin D can reduce circulating calcium and induce secondary hyperparathyroidism. The increase in PTH may induce weight gain, obesity and T2DM. Raised PTH is associated with abnormal glucose metabolism due to interference of PTH with either with ability of the pancreas to release insulin, the action of insulin or both. High PTH level causes suppression of insulin signal transduction in adipocytes that resulted in insulin resistance and high prevalence of diabetes mellitus (2 - 4 times) in hyperparathyroidism. ${ }^{9}$ Secondary hyperparathyroidism is a response to low calcium level related to hypovitaminosis $\mathrm{D}$.

The cause of osteoporosis is multifactorial, hyperparathyroidism and vitamin D deficiency are possible risk factor. 10 There is evidence that vitamin $\mathrm{D}$ inhibits fat accumulation, increases insulin synthesis and preserves pancreatic islet cells, decreases insulin resistance and reduces hunger, favouring better control of obesity and T2DM both. In bone metabolism, vitamin D increases the plasma levels of calcium and phosphorus, regulates osteoblast and osteoclast activity and combats PTH hypersecretion, promoting bone formation and preventing/treating osteoporosis.

\section{MATERIALS AND METHODS}

\section{Study Design}

Observational study.

\section{Study Setting}

Department of Medicine, BRD Medical College, Gorakhpur.

\section{Study Period}

January 2017 to December 2017.

\section{Study Subjects}

Clinically diagnosed case of type 2 Diabetes Mellitus of age group 45 - 65 yrs.

\section{Sample Size}

100 patients with Type 2 Diabetes Mellitus.

\section{Inclusion Criteria}

A total of 100 clinically diagnosed Type- 2 diabetic patients of age group 45 - 65 years, who were admitted in Department of Medicine, Nehru Hospital, BRD Medical College, Gorakhpur, UP from Jan 2017 to Dec 2017 were included in this study.

\section{Exclusion Criteria}

Type-2 diabetic patients with following conditions were excluded from the study-

1. Patients with extensive skin disorders (due to hampered vitamin D synthesis).

2. Post total thyroidectomy patients (because of absent parathyroid gland).

3. Critically ill patients (because of excess oxidative stress and impaired kidney function).

\section{Study Procedure}

The patients were selected as per inclusion criteria. An informed consent was taken. Detailed case history, examination and relevant investigations $(\mathrm{HbA} 1 \mathrm{C}$, urine microscopy, BMD, vitamin D, PTH etc.) were done for all patients. Data was collected using a semi-structured questionnaire by direct interview with patients and by clinical examination and from relevant investigations.

\section{Investigations}

1. HbA1C level (controlled $<7 \%$, uncontrolled $>7 \%$ ).

2. Serum PTH (normal $7-68 \mathrm{pg} / \mathrm{mL}$, increased $>68$ $\mathrm{pg} / \mathrm{mL}$ ).

3. Serum vitamin $\mathrm{D}$ (normal $>20 \mathrm{ng} / \mathrm{mL}$, low level $<20$ $\mathrm{ng} / \mathrm{mL}$ ).

4. BMD: Dual energy x-ray absorptiometry (DXA) scan at lumbar spine $\left(\mathrm{L}_{2}-\mathrm{L}_{4}\right)$ and dual femur (trochanter and femoral neck) was done and patients were categorised by using WHO criteria as:

- Normal BMD T-score: at or above -1 SD.

- Osteopenia T-score: between -1 and -2.5 SD.

- Osteoporosis T-score: at or below -2.5 SD.

\section{Statistical Analysis}

Data entry was done in IBM SPSS Statistics Version 22 and statistical analysis was done by using appropriate statistical tests like Fisher exact test and Pearson Chi-square test by descriptive statistics. $P$ value $<0.05$ is considered as statistically significant result.

\section{RESULTS}

There was high prevalence of abnormal BMD (total 62\%) in diabetic patients. The prevalence of osteoporosis (30\%) was more in uncontrolled diabetics (86.67\%), while osteopenia $(32 \%)$ was present in $68.75 \%$ of uncontrolled diabetics and $31.25 \%$ of controlled diabetics. Vitamin D deficiency was also more in $86.66 \%$ of uncontrolled diabetic patients as compared to controlled diabetics $(13.33 \%)$ ( $p$ value $=0.090$ ). In osteoporotic patients, $86.66 \%$ of patients had low vitamin $\mathrm{D}$ and $66.67 \%$ patients had raised $\mathrm{PTH}$, while in osteopenic patients $68.75 \%$ had low vitamin D and $37.50 \%$ had raised PTH ( $p$ value $=0.002$ ). Majority of the osteoporotic patients had raised PTH (66.67\%), while most of the osteopenic patients had normal PTH levels (56.25\%). 


\begin{tabular}{|c|c|c|c|}
\hline \multirow{2}{*}{ BMD } & \multirow{2}{*}{$\begin{array}{c}\text { No. of } \\
\text { Patients }\end{array}$} & $\begin{array}{c}\text { Controlled } \\
(\mathbf{N = 2 2})\end{array}$ & $\begin{array}{c}\text { Uncontrolled } \\
\text { (N=78) }\end{array}$ \\
\hline Normal & 38 & $8(21.05 \%)$ & $30(78.94 \%)$ \\
\hline Osteopenia & 32 & $10(31.25 \%)$ & $22(68.75 \%)$ \\
\hline Osteoporosis & 30 & $4(13.33 \%)$ & $26(86.67 \%)$ \\
\hline \multicolumn{3}{|c|}{ Table 1. Showing Correlation between BMD } \\
and Diabetes Control (HbA1C)
\end{tabular}

\begin{tabular}{|c|c|c|c|c|}
\hline \multirow{2}{*}{$\begin{array}{c}\text { Serum } \\
\text { Vitamin D }\end{array}$} & \multirow{2}{*}{$\begin{array}{c}\text { No. of } \\
\text { Patients }\end{array}$} & \multicolumn{2}{|c|}{ HbA1C } & Fisher's \\
\cline { 3 - 4 } & & $\begin{array}{c}\text { Controlled } \\
(\mathbf{N}=\mathbf{2 2})\end{array}$ & $\begin{array}{c}\text { Uncontrolled } \\
\text { (N=78) }\end{array}$ & $\begin{array}{c}\text { Exact } \\
\text { Test }\end{array}$ \\
\hline Normal & 40 & $14(35.00 \%)$ & $26(65.00 \%)$ & \\
\hline Low Level & 60 & $8(13.33 \%)$ & $52(86.66 \%)$ & $\mathrm{p}=0.090$ \\
\hline
\end{tabular}

Table 2. Correlation between Serum Vitamin D and Diabetes Control (HbA1C)

\begin{tabular}{|c|c|c|c|c|c|c|}
\hline \multirow{2}{*}{$\begin{array}{c}\text { Bone Mineral } \\
\text { Density }\end{array}$} & \multicolumn{2}{|c|}{ Vitamin D (N=100) } & \multicolumn{3}{|c|}{ PTH (N=100) } & $\begin{array}{c}\text { Pearson Chi- } \\
\text { Square Test }\end{array}$ \\
\cline { 2 - 7 } & Normal & Low Level & Normal & Decreased & Increased & \\
\hline Normal $(\mathrm{N}=38)$ & $23(68.42 \%)$ & $12(31.25 \%)$ & $36(94.73 \%)$ & $0(0 \%)$ & $2(5.26 \%)$ & \\
\hline Osteopenia (N=32) & $10(31.25 \%)$ & $22(68.75 \%)$ & $18(56.25 \%)$ & $2(6.25 \%)$ & $12(37.5 \%)$ & P=0.002 \\
\hline Osteoporosis (N=30) & $4(13.33 \%)$ & $26(86.66 \%)$ & $10(33.33 \%)$ & $0(0 \%)$ & $20(66.67 \%)$ & (N) \\
\hline
\end{tabular}

Table 3. Correlation between Vitamin D, PTH with BMD in Type-2 Diabetic Patients $(\mathrm{N}=100)$

\section{DISCUSSION}

As shown above, we have studied the correlation of PTH and vitamin D with BMD among 100 type- 2 diabetic patients. As shown in Table 1, $30(30 \%)$ patients had osteoporosis in which $26(86.67 \%)$ had uncontrolled diabetes and 4 had (13.33\%) controlled diabetes. Among 32 (32\%) patients with osteopenia, $22(68.75 \%)$ had uncontrolled diabetes and 10 (31.25\%) had controlled diabetes. This signifies that the uncontrolled diabetes carries a major risk of abnormal BMD. Similar studies done by Schwartz et al $^{11}$ in a large prospective study of older women obtained from the Study of Osteoporotic Fractures confirmed that women with type 2 diabetes experience higher fracture rates than non-diabetic women. Study by Gregorio et $\mathrm{al}^{3}$ also conform that bone loss has been observed to be greater in patients with poorly controlled diabetes than in those whose diabetes is in good control. Study by Mima et al $^{12}$ also showed that diabetes mellitus is associated with osteoporosis.

As shown in Table 2, among 40 (40\%) patients with normal Vitamin D 14 (35\%) patients had controlled Diabetes and $26(65 \%)$ patients had uncontrolled Diabetes and 60 $(60 \%)$ with low vitamin D, 8 (13.33\%) had controlled diabetes and $52(86.66 \%)$ had uncontrolled diabetes. It was found that vitamin D deficiency was more common in uncontrolled diabetic patients $(86.66 \%)$ ( $p$ value $=0.090)$. Similarly, in a study by Mohammad Alhumaidi et al,13 it was found that prevalence of vitamin D deficiency is $76.6 \%$ in diabetic patients.

In Table 3 among 30 patients with osteoporosis, 26 (86.67\%) had low vitamin D and 4 (13.33\%) had normal vitamin D level in this group of osteoporotic patients, 20 (66.67\%) had increased PTH, 10 (33.33\%) had normal PTH. In this group of 20 patients in whom vitamin D was decreased and PTH was raised all were osteoporosed, while in 4 cases with osteoporosis, neither vitamin D was decreased nor PTH was raised. This signifies that osteoporosis also depend on some other factors like increasing age, female gender, menopause, low BMI, low calcium diet, lack of exercise, decreased sunlight exposure, medications like steroid, glitazones etc. Patients who had both raised PTH and low vitamin D were more prone to develop osteoporosis than the patients who had either raised PTH or low Vitamin D alone.

Similarly, in 32 patients with osteopenia, 22 (68.75\%) had low vitamin D and 10 (31.2\%) had normal vitamin D. In this group of patients, only $12(37.5 \%)$ had increased PTH and $18(56.25 \%)$ had normal PTH which signifies that low vitamin D level is the better predictor of osteopenia than PTH level. By these findings, we can predict that those patients who had both low level of vitamin D and increased PTH will be osteoporosed or osteopenic. It means that PTH and vitamin $\mathrm{D}$ together are better predictors of osteoporosis or osteopenia.

Similar results were shown by many other studies. The study done by Sahota et al14 found that prevalence of hypovitaminosis D was $39 \%$ and not all patients with hypovitaminosis D develop secondary hyperparathyroidism. Patel et $\mathrm{al}^{15}$ suggested that glomerular filtration rate is the single most important factor in maintaining PTH levels. Gunnarsson et al, ${ }^{16}$ while supporting the kidney function hypothesis, felt that body mass index may play a role in women by blunting the level of PTH and added that in men insulin-like growth factor 1 , smoking and testosterone levels may do the same. The World Health Organisation (WHO) ${ }^{17}$ described a serum level of 25-OHD of $20 \mathrm{ng} / \mathrm{mL}(50 \mathrm{nmol} / \mathrm{L})$ as deficiency ${ }^{17}$ and a level of $30 \mathrm{ng} / \mathrm{mL}(75 \mathrm{nmol} / \mathrm{L})$ as normal, because at this level PTH drops down to normal levels. At present it is believed that below $30 \mathrm{ng} / \mathrm{mL}$ of 25 OHD, the level of PTH should start rising. ${ }^{18} \mathrm{~A}$ study done by Chang et $\mathrm{al}^{9}$ shows that high level of PTH is associated with abnormal glucose metabolism due to interference of PTH either with ability of the pancreas to release insulin, the action of insulin or both. High PTH level causes suppression of insulin signal transduction in adipocytes that resulted in insulin resistance and high prevalence of diabetes mellitus (2-4 times) in hyperparathyroidism. Study by Erika et al showed in osteoporosis, prevalence of low vitamin D is 53\% and one-third of postmenopausal women with osteoporosis had elevated PTH. Increased PTH was observed in 35\% and vitamin D deficiency in $55 \%$ cases by Cerda et al.

\section{CONCLUSION}

1. Osteoporosis or osteopenia was more common in patients with uncontrolled Diabetes mellitus.

2. Patients with uncontrolled diabetes had significantly more microvascular complications, which caused decreased mineralisation of bone and increased risk of osteoporosis.

3. Vitamin D deficiency (86.66\%) was found mainly in patients with uncontrolled diabetes, which signifies that low vitamin D may be one of the causes of poor control of diabetes and vitamin D supplementation is necessary for better control of diabetes. 
4. Most of the patients with osteoporosis had raised PTH with low vitamin D level both of which further worsens blood sugar control.

5. By this study we can predict that in those patients who had both low level of vitamin D and increased PTH were more prone to develop osteoporosis or osteopenic. It means that PTH and vitamin D together are better predictors of osteoporosis or osteopenia.

\section{ACKNOWLEDGEMENT}

We express our sincere thanks and gratitude to our Associate Professor and PG Residents for their valuable support. I also express my sincere thanks to Department of Pathology and Radiology for proving all the relevant investigations.

\section{REFERENCES}

[1] American Diabetes Association. Diagnosis and classification of diabetes mellitus. Diabetes Care 2012;35 (Suppl 1):S64-S71.

[2] Yamagishi $S$, Nakamura $K$, Inoue $H$. Possible participation of advanced glycation end products in the pathogenesis of osteoporosis in diabetic patients. Medical Hypotheses 2005;65(6):1013-5.

[3] Gregorio F, Cristallini S, Santeusanio F, et al. Osteopenia associated with non - insulin - dependent diabetes mellitus: What are the causes? Diabetes Res Clin Pract 1994;23(1):43-54.

[4] NIH Consensus Development Panel on Osteoporosis Prevention, Diagnosis and Therapy. Osteoporosis prevention, diagnosis and therapy. The Journal of the American Medical Association 2001;285(6):785-95.

[5] Thrailkill KM, Lumpkin CK, Bunn RC, et al. Is insulin an anabolic agent in bone? Dissecting the diabetic bone for clues. American Journal of Physiology, Endocrinology and Metabolism 2005;289(5):E735E45.

[6] Brown SA, Sharples JL, Osteoporosis: an underappreciated complication of diabetes. Clinical Diabetes 2004;22(1):10-20.

[7] Vestergaard P. Discrepancies in bone mineral density and fracture risk in patients with type 1 and type 2 diabetes-a meta-analysis. Osteoporosis International 2007;18(4):427-44.
[8] Chau DL, Goldstein-Fuchs J, Edelman SV. Osteoporosis among patients with diabetes: an overlooked disease. Diabetes Spectrum 2003;16(3):176-82.

[9] Chang E, Donkin SS, Teegarden D. Parathyroid hormone suppresses insulin signaling in adepocytes. Mol Cell Endocrinol 2009;307(1-2):77-82.

[10] Harinarayan CV, Sachan A, Reddy PA, et al. Vitamin D status and bone mineral density in women of reproductive and postmenopausal age groups: a crosssectional study from south India. J Assoc Physicians India 2011;59:698-704.

[11] Schwartz AV, Sellmeyer DE, Ensrud KE, et al. Older women with diabetes have an increased risk of fractures: a prospective study. J Clin Endocrinol Metab 2001;86(1):32-8.

[12] Meema HE, Meema S. The relationship of diabetes mellitus and body weight to osteoporosis in elderly females. Can Med Assoc J 1967;96(3):132-9.

[13] Alhumaidi M, Agha A, Dewish M. Vitamin D deficiency in patients with type-2 diabetes mellitus in southern region of Saudi Arabia. Maedica (Buchar) 2013;8(3):231-6.

[14] Sahota O, Mundey MK, San P, et al. Vitamin D insufficiency and the blunted PTH response in established osteoporosis: the role of magnesium deficiency. Osteoporos Int 2006;17(7):1013-21.

[15] Patel S, Hyer S, Barron J. Glomerular filtration rate is a major determinant of the relationship between 25hydroxyvitamin $\mathrm{D}$ and parathyroid hormone. Calcif Tissue Int 2007;80(4):221-6.

[16] Gunnarsson O, Indridason OS, Franzson L, et al. Factors associated with elevated or blunted PTH response in vitamin D insufficient adults. J Int Med 2009;265(4):488-95.

[17] WHO Scientific Group. Prevention and Management of Osteoporosis: report of a WHO scientific group. Geneva: WHO. Technical Report Series 2003;921:1164.

[18] Wallace AM, Gibson S, de la Hunty A, et al. Measurement of 25-hydroxyvitamin D in the clinical laboratory: current procedures, performance characteristics and limitations. Steroids 2010;75(7):477-88. 